FÁBREGA, Jorge; MORALES, Ana María; MUÑOZ, Nicolás "Delito y especialización en Chile".

Polít. crim. Vol. 9, № 18 (Diciembre 2014), Art. 7, pp. 521-542.

[http://www.politicacriminal.cl/Vol_09/n_18/Vol9N18A7.pdf]

\title{
Delito y especialización en Chile
}

Jorge Fábrega Lacoa

Economista y Sociólogo PUC,

Phd en Políticas Públicas, Universidad de Chicago,

Profesor de la Escuela de Gobierno de la Universidad Adolfo Ibáñez

jorge.fabrega@uai.cl

Ana María Morales Peillard

Abogado Universidad de Chile,

Magíster en Política Criminal, London School of Economics and Political Science, Directora del Área de Justicia y Reinserción de la Fundación Paz Ciudadana amorales@pazciudadana.cl

Nicolás Muñoz Correa

Economista Universidad de Chile,

Magister en Políticas Públicas de la Universidad de Chile,

Investigador Área de Justicia y Reinserción de la Fundación Paz Ciudadana

nmunoz@pazciudadana.cl

\section{Resumen}

¿En qué delito se reincide cuando se reincide? En este trabajo se analizan los patrones de reincidencia de la población condenada a una pena privativa de libertad en Chile. Para ello se identifican subgrupos de reincidentes que se especializan en cada tipo de delito. El análisis se realiza en base a los datos de ingreso y egreso a un recinto penitenciario de la población penal entre el 2007 y el 2010 provistos por Gendarmería de Chile. Los resultados indican que un $65 \%$ de la población reincidente se especializa en alguna categoría delictual. Tres categorías (hurto, robos no violentos y robos) de diecisiete posibles concentran el 50\% de la especialización delictiva. Existen diferencias estadísticamente significativas en los niveles de especialización según la edad y género del condenado. Por último, la probabilidad que un reincidente esté especializado en un tipo de delito es prácticamente igual a uno con posterioridad de la tercera reincidencia.

Palabras clave: Reincidencia, especialización, carreras criminales, trayectorias delictivas.

\begin{abstract}
What crime recurs with recidivism? This paper analyses the patterns of recidivism among the population sentenced to imprisonment in Chile. For this purpose, subgroups of offenders who specialize in each type of crime are identified. The analysis is based on data of imprisonment between 2007 and 2010 provided by the Chilean Gendarmerie. The results indicate that $65 \%$ of the recidivist population will specialize in some criminal category.
\end{abstract}


FÁBREGA, Jorge; MORALES, Ana María; MUÑOZ, Nicolás “Delito y especialización en Chile".

Three of seventeen possible categories (burglary, theft and nonviolent robbery) concentrate $50 \%$ of criminal specialization. There were statistically significant differences in levels of specialization by age and gender of the offender. Finally, the probability that an offender is specialized in one type of criminal category tends to one after his third recidivism.

Key words: Recidivism, specialization, criminal careers, criminal trajectories.

\section{Introducción}

Desde 2010, cada año ha habido aproximadamente cuarenta mil personas recluidas en algún recinto carcelario del país en calidad de condenadas (no obstante, a diciembre del 2013, de acuerdo a cifras oficiales de Gendarmería de Chile, este número cayó a 32.500 personas). De acuerdo a Morales et al., ${ }^{1}$ cuando salgan de la cárcel, aproximadamente un $70 \%$ será nuevamente formalizado y un $50 \%$ retornará a ella dentro de los tres años siguientes a su egreso por una nueva condena.

Esto último sugiere que las dificultades de reinserción e integración social de la población penal son severas. En este sentido, para el diseño de políticas públicas en materia de seguridad ciudadana, es útil que se estudien las carreras criminales de los reincidentes, identificando patrones asociados a la formación de carreras especializadas o diversificadas. Este artículo contribuye a esos esfuerzos estudiando las carreras que caracterizan a los reincidentes en el sistema penitenciario chileno, determinando cómo éstos están asociados a la especialización delictual en categorías específicas de delitos. En particular, el estudio responde a las preguntas siguientes: ¿Qué porcentaje de los reincidentes se especializa en una categoría delictual? ¿Qué tipos de delitos son más afines al desarrollo de especialización delictual? y ¿Cuánto varía la probabilidad de especialización en un tipo específico de infracción con la edad, el género y cada sucesiva condena?

Comprender el grado en que un infractor puede especializarse en términos delictivos tiene importantes implicancias en materia de política pública. Si se conocen los patrones de especialización delictual de éstos, sería factible predecir de mejor manera el comportamiento esperado al egreso de la cárcel y facilitar la toma de decisiones a los policy-makers. ${ }^{2}$ Así, entender la especialización delictual podría tener un efecto en las políticas de prevención y de persecución de la delincuencia, además de las políticas de reinserción dirigidas a la población penal ${ }^{3}$ o dicho de otra manera, se podría aumentar la eficiencia del sistema de justicia criminal, toda vez que sería posible focalizar recursos de acuerdo al comportamiento esperado de subsegmentos de la población que han cometido o están en riesgo de cometer nuevos delitos.

\footnotetext{
${ }^{1}$ MORALES, A., MUÑOZ, N., WELSCH, G. y FÁBREGA, J., La reincidencia en el sistema penitenciario chileno. Santiago, Chile: Fundación Paz Ciudadana, Hanns Seidel Stiftung y Universidad Adolfo Ibánez, 2012.

${ }^{2}$ PIQUERO, A., OSTER, R., MAZEROLlE, P., BRAME, R. y DEAN, Ch., "Onset age and offense specialization", Journal of Research in Crime and Delinquency, 36:3 (1999), pp. 275-299.

${ }^{3}$ BLUMSTEIN, A., COHEN, J. y FARRINGTON, D., "Criminal career research: Its value for criminology", Criminology, 26: 1 (1988), pp. 1-35; LATTIMORE, P., VISHER, Ch. y LINSTER, R. "Specialization in Juvenile Careers: Markov Results for a California Cohort", Journal of Quantitative Criminology, 10 (1994), pp. 291-316.
} 
Por ende, avanzar hacia una comprensión más detallada de los patrones de especialización de la población reincidente es de utilidad para las distintas etapas del sistema judicialpenal. ${ }^{4}$ Por ejemplo, con excepción de los casos de detenciones emanadas de órdenes judiciales, tanto las policías como el Ministerio Público se verían beneficiados de conocer estos patrones para efectos de desarrollar su labor de análisis e investigación criminal. Esta información también podría ser de utilidad para la judicatura porque pone a su disposición antecedentes valiosos para discernir en casos específicos cuál sentencia es la más apropiada dentro del rango de posibilidades que corresponda a un juicio determinado. Por último, Gendarmería de Chile también podría utilizar esta información para la toma de decisiones asociadas a las labores de clasificación de los internos dentro de los recintos carcelarios y en la implementación de programas de reinserción, entre otras consideraciones.

El resto del trabajo está organizado en cuatro secciones. En la primera sección se revisa la literatura existente en relación a la especialización delictiva. La segunda sección detalla la metodología y datos utilizados. La tercera sección propone una estimación de la especialización delictual de los reincidentes y estima los efectos de la reiteración en la reincidencia, el historial delictual, el género, la edad y la duración de la última condena en la probabilidad que una persona se especialice en una categoría delictual. A partir de esos análisis se vuelven a estimar los efectos marginales de las variables explicativas sobre la probabilidad de la especialización. La última sección resume las principales conclusiones del estudio.

\section{La especialización delictual en los estudios de criminalidad}

Una carrera criminal puede definirse como "la secuencia longitudinal de delitos cometidos por un infractor que tiene una tasa de comisión de delitos detectable en cierto período de tiempo". Tal carrera puede ser (i) diversificada, en cuyo caso, el infractor comete delitos asociados a distintas tipologías, o (ii) especializada. La especialización delictual es la tendencia a cometer la misma tipología de delitos en períodos sucesivos de tiempo. ${ }^{6}$ Existen varios enfoques criminológicos que abordan el estudio de las carreras criminales y la especialización. Moffitt ${ }^{7}$ elaboró una taxonomía basándose en la criminología del desarrollo, clasificando a los infractores de acuerdo a su comportamiento delictual durante su ciclo de vida, identificando dos grupos: (a) los infractores con conducta delictiva limitada sólo a su adolescencia y (b) los infractores con conducta delictiva persistente en su ciclo de vida. En términos de la especialización, a partir de los hallazgos de sus investigaciones, se plantea que en general existe una ausencia de especialización en aquellos infractores que sólo cometen delitos durante su adolescencia -tendiendo a una mayor versatilidad delictual-, mientras que el caso de los infractores persistentes en su

\footnotetext{
4 Véase Capítulo 6 de BLUMSTEIN, A., COHEN, J.; ROTH, J. y VISHER, C., Criminal careers and "career criminals". Report of the Panel on Research on Criminal Careers, National Research Council. Washington, D.C.: National Academy Press, 1986.

${ }^{5}$ BLUMSTEIN/COHEN/FARRINGTON, "Specialization", cit. nota n 3, p. 2.

${ }^{6}$ BLUMSTEIN/COHEN/ ROTH/ VISHER, "Criminal careers", cit. nota ${ }^{\circ} 4$.

${ }^{7}$ MOFFITT, T., "Adolescence-Limited and Life-Course Persistent Antisocial Behavior: A Developmental Taxonomy”, Psychological Review, 100 (1993), pp. 674-701.
} 
ciclo vida, se observa la presencia de una fuerte especialización. Por su parte, Loeber et al. ${ }^{8}$ -basándose al igual que Moffitt en la criminología del desarrollo- identificaron tres tipos de trayectorias delictuales, ${ }^{9}$ que escalan en nivel de gravedad. La primera trayectoria (conflicto a la autoridad) se caracterizaría por presentar patrones de comportamientos desafiantes y obstinados en un inicio, para luego progresar a conductas desobedientes, con el desacatamiento de normas al interior de la familia y la sociedad, tales como el absentismo escolar, permanecer largas horas fuera del hogar, etc. La segunda trayectoria (abierta) se iniciaría con el desarrollo de actitudes deshonestas acompañadas de infracciones menores, tales como el hurto de cosas menores y vandalismo para progresar luego hacia conductas más serias como asaltos, robos y delitos económicos como el fraude. Finalmente, la tercera trayectoria (encubierta) se inicia con actitudes agresivas que se van intensificando hacia conductas que derivan en agresiones físicas y verbales, desencadenando a futuro la comisión de delitos violentos, como robos con intimidación o con porte ilegal de armas y violación. Si bien en cada trayectoria se observa un escalamiento gradual en la gravedad de las conductas, también el desarrollo de cada una de dichas trayectorias refleja una estrecha relación con determinados grupos delictuales, ofreciendo un marco teórico y empírico para el desarrollo de investigaciones en torno a la especialización.

A nivel empírico, si bien una parte importante de la población juvenil declara haber participado en alguna actividad ilícita de manera ocasional, ${ }^{10}$ en el largo plazo, sólo una pequeña proporción lo sigue haciendo activamente. Estos son "infractores persistentes", personas caracterizadas por presentar un largo registro de hechos delictuales durante su adolescencia y edad adulta. ${ }^{11}$ En este sentido, el foco de las investigaciones ha sido estudiar el comportamiento de estos infractores persistentes identificando tendencias a la especialización o diversificación. Al respecto, la evidencia es congruente con la existencia de trayectorias delictuales que en la etapa juvenil muestran dispersión ${ }^{12}$ y que en etapa adulta muestran especialización en categorías específicas de delitos. ${ }^{13}$ Para explicar estas

\footnotetext{
${ }^{8}$ LOEBER, R., FARRINGTON, D., STOUTHAMER-LOEBER, M., MOFFITT, T. y CASPI, A., "The development of male offending: Key findings from the first decade of the Pittsburgh Youth Study", Studies on Crime and Prevention, 7 (1998), pp. 141-171.

${ }^{9}$ El concepto de "trayectoria" es utilizado preferentemente por los teóricos de la criminología del desarrollo como un homólogo del de "carrera criminal", pero con énfasis en el impacto que pueden tener las experiencias tempranas de la niñez y adolescencia en las carreras criminales persistentes. SOOTHILL, K., FITZPATRICK, C. y FRANCIS, B., Understanding Criminal Careers, Cullompton, Devon: Willan, 2009.

${ }^{10}$ LO, C., KIM, Y. y CHENG, T., "Offense specialization of arrestees: An event history analysis", Crime and Delinquency, 54: 3 (2008), pp. 341-365.

${ }^{11}$ BARLOW, H. y FERDINAND, T., Understanding delinquency, New York: Harper Collins, 1992; MOFFITT, "Adolescence-Limited", cit. nota $\mathrm{n}^{\circ} 7$.

${ }^{12}$ KLEIN, M., "Offense specialization and versatility among juveniles", British Journal of Criminology, 24 (1984), pp. 185-194; PIQUERO, A., "Frequency, specialization, and violence in offending careers", Journal of Research in Crime and Delinquency, 37:4 (2000), pp. 392-418; PIQUERO, A. y BUKA, S., "Linking juvenile and adult patterns of criminal activity in the Providence cohort of the National Collaborative Perinatal Project", Journal of Criminal Justice, 30: 4 (2002), pp. 259-272; LO/KIM/CHENG, "Offense specialization", cit. nota ${ }^{\circ} 10$.

${ }^{13}$ BRITT, C., "The measurement of specialization and escalation in the criminal career: An alternative modeling strategy", Journal of Quantitative Criminology, 12:2 (1996), pp. 193-222; LO/KIM/CHENG, "Offense specialization", cit. nota $n^{\circ} 10$.
} 
trayectorias, los estudios, sobre la base de datos a nivel individual, ${ }^{14}$ se han concentrado en variables que pueden agruparse en cuatro categorías: a) variables asociadas al pasado conductual del infractor, b) variables sociodemográficas, c) variables contextuales, tales como, el consumo de drogas y la situación laboral de la persona y d) la identificación de clústeres delictivos.

En relación al estudio del comportamiento pasado y sus efectos sobre la especialización, Lo et al. ${ }^{15}$ analizaron (i) si el tipo de delito cometido en el inicio de la vida delictual, el volumen de delitos cometidos con anterioridad o la categoría delictual del último delito cometido por un infractor son buenos predictores de los delitos cometidos con posterioridad, y (ii) si existen patrones de especialización delictual determinados por características sociodemográficas de éstos. Para ello, utilizaron datos de entrevistas realizadas a personas entre 18 y 25 años detenidas entre los años 1999 y 2001 en el estado de Ohio, Estados Unidos, así como registros de su historial de detenciones. Sus resultados aportan evidencia de la existencia de especialización asociada a categorías específicas de delitos. Además, según sus estimaciones, a mayor número de delitos previos, mayor es la probabilidad de ocurrencia de la comisión del mismo delito: la probabilidad de cometer un delito contra la propiedad aumenta en $49 \%$ por cada delito contra la propiedad adicional cometido con anterioridad; mientras que para los delitos violentos, de drogas y otros misceláneos, las probabilidades aumentan en $339 \%, 218 \%$ y $88 \%$, respectivamente. No obstante lo anterior, si bien para todas las tipologías estudiadas, el penúltimo delito cometido se asocia fuertemente al delito cometido bajo estudio, una vez se controla por otras variables de interés, sus impactos pierden significancia estadística.

Con estos resultados, Lo et al. ${ }^{16}$ concluyeron que existe evidencia robusta respecto a la existencia de especialización probabilística (en términos del número de delitos cometidos con anterioridad), pero limitada respecto a la especialización secuencial (en términos del penúltimo delito cometido). Además, el estudio entrega evidencia a favor de la existencia de trayectorias criminales respecto a los infractores por delitos de drogas, los cuales cometerían, además de estos delitos, un mix de otros ilícitos, tales como delitos contra la propiedad y otros misceláneos. En este sentido, la mayor dispersión delictual se presentaría en aquellos infractores clasificados en la trayectoria encubierta, que corresponden a infractores por delitos contra la propiedad y otros misceláneos, mientras que la mayor especialización se representaría en infractores por delitos violentos.

Por su parte, las variables sociodemográficas, con excepción de la edad, no muestran resultados robustos en la evidencia internacional. Para Lo et al., ${ }^{17}$, el género y la etnia no parecieran determinar un patrón de conducta tendiente a la especialización, cuestión que sería consistente con otros estudios realizados en la materia. ${ }^{18}$ Entre otras variables

\footnotetext{
${ }^{14}$ Para una mirada a nivel de agregación mayor véase, por ejemplo, Andresen (2009) quien analiza la especialización delictual al nivel de la localidad. ANDRESEN, M., "Crime Specialization across the Canadian Provinces". Revue canadienne de criminologie et de justice pénale, 51:1 (2009), pp. 31-53.

${ }^{15} \mathrm{LO} / \mathrm{KIM} / \mathrm{CHENG}$, "Offense specialization", cit. nota $\mathrm{n}^{\circ} 10$.

${ }^{16} \mathrm{LO} / \mathrm{KIM} / \mathrm{CHENG}$, "Offense specialization", cit. nota $\mathrm{n}^{\circ} 10$.

${ }^{17}$ LO/KIM/CHENG, "Offense specialization", cit. nota ${ }^{\circ} 10$.

${ }^{18}$ PIQUERO/BUKA, "Linking juvenile", cit. nota n ${ }^{\circ} 12$.
} 
sociodemográficas, la única que parece mostrar efectos en la especialización es el nivel de escolaridad del infractor, pero éstos se asocian sólo a algunas categorías de delito. ${ }^{19}$

Una tercera línea de investigación ha indagado en los efectos que puede tener sobre la comisión de delitos y la especialización en relación a variables tales como la situación laboral, el estar o no en una relación sentimental y el consumo de alcohol y otras drogas. Por ejemplo, McGloin et al. ${ }^{20}$ investigaron si la "estructura de oportunidades" incide en la especialización delictual. El objetivo de los autores fue comprender cómo ciertas circunstancias de las personas ${ }^{21}$ pueden afectar las oportunidades que se les presentan para delinquir. ${ }^{22}$ Para ello, estudiaron una muestra de población condenada a una pena privativa de libertad en el estado de Nebraska, Estados Unidos, durante los años 1989 y 1990, de la cual se obtuvo información por medio de un instrumento que caracterizó los meses previos al arresto que dio lugar a la condena. Los autores utilizaron dos modelos de análisis: El primero estimó si ciertas circunstancias de las personas predicen el grado de especialización delictual, mientras el segundo evaluó si el número de delitos pasados de cada infractor, variable considerada como proxy de una mayor propensión delictual, interactúa con las circunstancias a nivel local modificando su impacto en el grado de especialización.

Los resultados muestran que la adición de la variable asociada al número de delitos pasados como variable de control no alteró sustancialmente la relación entre las circunstancias a nivel local y la especialización delictual; relación que muestra que cambios en la supervisión comunitaria, en el estado marital, y en el consumo de alcohol y drogas están relacionados con cierto grado de diversidad delictual. A partir de ello, los autores sugieren que cambios en determinadas circunstancias en la vida de las personas podrían alterar sus actividades y rutinas, modificando de esta forma, las oportunidades que se les presentan para participar en determinada actividad delictual. Por ejemplo, cambios relacionados con un mayor consumo de alcohol y drogas parecieran aumentar la probabilidad de diversificación delictual, hecho que podría estar reflejando una exposición a un grupo de pares más extenso, dando como resultado un incremento a la exposición de oportunidades que pudiesen presentarse para delinquir.

En este contexto, McGloin et al. ${ }^{23}$ concluyeron que la diversificación y especialización delictual está condicionada por la naturaleza motivacional para delinquir así como por los

\footnotetext{
${ }^{19}$ LO/KIM/CHENG, “Offense specialization”, cit. nota ${ }^{\circ} 10$.

${ }^{20}$ McGLOIN, J., SULLIVAN, C., PIQUERO, A. y PRATT, T., "Local life circumstances and offending specialization/versatility: Comparing opportunity and propensity models", Journal of Research in Crime and Delinquency, 44:3 (2007), pp. 321-346.

${ }^{21}$ Circunstancias consideradas a la presencia de una determinada estructura de incentivos y oportunidades para las personas, que inhiben un comportamiento delictual. Los atributos medidos en esta dimensión correspondieron a variables relacionadas si el sujeto trabajaba o no, si vivía con su pareja o no, si bebía frecuentemente o no, si consumía drogas con regularidad o no, y si estaba bajo supervisión comunitaria o no (libertad condicional o alguna pena no privativa de libertad).

${ }^{22}$ Véase también SAMPSON, R. y LAUB, J., "A Life-Course View of the Development of Crime", Annals of the American Academy of Political and Social Science, 602 (2005), pp. 12-45; LAUB, J. y SAMPSON, R., Shared Beginnings, Divergent Lives: Delinquent Boys to Age 70. Cambridge, MA: Harvard University Press, 2005; FARRINGTON, D., "The Integrated Cognitive Antisocial Potential (ICAP) Theory", en: FARRINGTON, David (Ed.), Advances in Criminological Theory, Integrated Developmental \& Life-Course Theories of Offending, New Brunswick, NJ: Transaction Publishers, 2005.

${ }^{23}$ MCGLOIN/SULLIVAN/PIQUERO/PRATT, “Local life circumstances”, cit. nota n 20.
} 
contextos situacionales en los cuales se encuentran insertados. Por lo mismo, ampliar la línea de trabajo en el ámbito contextual es un gran paso para entender el comportamiento tanto de los infractores de ley como de lo que ocurre para cada tipo de delito. ${ }^{24}$

Por último, estudios recientes han enfocado el fenómeno de la especialización como uno de interacción compleja entre variables y, por ende, en vez de utilizar técnicas de regresión estadística que intentan aislar el efecto de cada variable sobre el fenómeno de la especialización, estudian cómo las distintas variables interactúan hasta formar patrones identificables. Por ejemplo, Tumminello et al. ${ }^{25}$ analizaron la especialización en la población infractora en la ciudad de Estocolmo, Suecia, entre 1991 y 2007. Los autores utilizaron técnicas de análisis de redes para determinar el grado de especialización en la conducta delictiva de las personas e identificaron clústeres de infractores que presentan características similares. Los autores obtuvieron evidencia de la existencia de un patrón de especialización según edad y género de los infractores, donde mujeres y personas de mayor de edad tenderían a especializarse en una mayor proporción. Pero, en concordancia con las investigaciones comentadas anteriormente constataron la existencia de un "efecto cohorte", en el sentido que la población más joven tiende a componerse por infractores con un comportamiento más diversificado, mientras la población de mayor edad relativa presentaría comportamientos más especializados. Junto a lo anterior, los autores identificaron la existencia de clústeres de delitos "tradicionales", tales como los delitos de hurto y robo, delitos violentos, delitos de drogas y delitos económicos (particularmente, fraudes). Conforme a esta evidencia y a lo observado en el análisis espectral, Tumminello et al. ${ }^{26}$ ofrecieron evidencia consistente con la hipótesis propuesta de que existiría un número limitado de infractores que se especializan, cuestión que se apreciaría solamente en determinadas tipologías de delitos.

En resumen, los estudios a nivel internacional sugieren que la especialización delictual está asociada sólo a algunos delitos, además parece existir evidencia suficiente para esperar que la especialización aumente con la edad del infractor. El conocimiento de los registros históricos de un infractor parece ser un buen predictor de su comportamiento futuro y la evidencia respecto al efecto de variables sociodemográficas como género y etnicidad es mixta.

\section{Metodología y descripción de los datos}

Los estudios sobre especialización a nivel internacional revisados en la sección anterior sugieren que la propensión hacia la especialización delictual puede ser entendida como una función del historial de delitos previos, las tipologías de dichos delitos y la edad del potencial infractor, entre otras variables de interés. Por lo tanto, para el caso chileno, el desafío es estimar una función del siguiente tipo:

\footnotetext{
${ }^{24}$ GOTTFREDSON, M., "Offender Classifications and Treatment Effects in Developmental Criminology: A Propensity/Event Consideration”, Annals of the American Academy of Political and Social Science, 602 (2005), pp. 46-57.

25 TUMMINELlO, M., EDLING, C., LILJEROS, F., MANTEGNA, R. y SARNECKI, J., "The phenomenology of specialization of criminal suspects", PLoS ONE, 8:5 (2013), pp. 1-8.

${ }^{26}$ TUMMINELLO/EDLING/LILJEROS/MANTEGNA/SARNECKI, “The phenomenology", cit. nota n 25.
} 
FÁBREGA, Jorge; MORALES, Ana María; MUÑOZ, Nicolás “Delito y especialización en Chile".

Probabilidad de especialización $=f($ registro de delitos previos según tipología de delito,
edad del individuo, género, otras variables sociodemograficas, ... $)$

En esta sección se explican las decisiones metodológicas que se tomaron para estimar la propensión hacia la especialización delictual en la población penal chilena en una relación como la descrita en la ecuación anterior. Primero, se describe a la población penal reincidente. Posteriormente, se describe la estrategia utilizada para distinguir a la población penal reincidente con especialización delictual de la que no lo es.

\subsection{Reincidencia penitenciaria}

La especialización delictual es una categoría aplicable a un subconjunto de la población que reincide delictualmente. Por ello, es de suma importancia, definir en primera instancia cómo se ha de determinar si una persona es reincidente o no. A nivel conceptual, la reincidencia pareciera ser una variable sencilla; no obstante, su operacionalización ha sido objeto de extensos debates. Por ejemplo, se han propuesto varios criterios para definir cuál debe ser el período de observación (o seguimiento) de un sujeto para determinar si es considerado o no como reincidente; también existen varias instancias que pueden ser consideradas como hitos para clasificar a una persona como reincidente (por ejemplo, ¿un sujeto es reincidente cuando comete un nuevo delito?, ¿lo es al momento de la detención?, ¿o cuándo es condenado?); por último, tampoco existe un estándar para definir cuál debe ser el universo poblacional a considerar en las respectivas mediciones. Así, para definir operacionalmente qué se entiende por reincidencia existen varias opciones igualmente válidas que destacan distintos aspectos del fenómeno.

En el presente estudio se optó por analizar la reincidencia asociada a una condena, esto es, aquella que se produce cuando un condenado egresado de la cárcel retorna a ésta por una nueva condena privativa de libertad. Entre las alternativas existentes, esta manera de medir la reincidencia establece el filtro más exigente en la medición de este indicador, toda vez que excluye los casos en que pudo existir reincidencia y ésta no fue detectada por el sistema judicial-penal y aquellos donde sí se formalizó la investigación respecto de un imputado pero la evidencia no fue suficiente para determinar la ocurrencia de los hechos delictivos o la participación del imputado en ellos. ${ }^{27}$

Específicamente, en este estudio se analiza a la población condenada que egresó de recintos penitenciarios del país durante el año 2007, siguiéndola por un período de tres años contados desde la fecha de egreso. ${ }^{28}$ Se consideró a una persona reincidente si la persona fue encarcelada nuevamente en dicho período de tiempo bajo la calidad procesal de condenado. De acuerdo a los datos, durante el año 2007, egresaron de la cárcel un total de 16.911 personas, de las cuales, el 50,5\% reincidió (8.537 personas). Del total de reincidentes, 6 de cada 10 sujetos reincidieron dentro de los primeros 12 meses posterior a su egreso, lográndose evidenciar que el $25 \%$ de este total lo hizo en 100 días o menos. La

\footnotetext{
${ }^{27}$ Para un análisis extenso de esta discusión véase MORALES/MUÑOZ/WELSCH/FÁBREGA, La reincidencia, cit. nota $\mathrm{n}^{\circ} 1$.

${ }^{28}$ Los datos fueron provistos por Gendarmería de Chile.
} 
distribución por género de los reincidentes es proporcional a los tamaños de la población penitenciaria ( $88 \%$ de hombres y $11 \%$ de mujeres) y poco menos del $60 \%$ corresponde a personas de 29 o menos años de edad. Por otra parte, un 55\% no posee antecedentes de condenas privativas de libertad anteriores. En relación a la tipología de delitos por la que habían egresado de la cárcel, dos de cada tres reincidentes había egresado tras cumplir una condena relacionada con algún delito contra la propiedad (hurto, robo violento o robo no violento). El anexo detalla la distribución de la población reincidente para un conjunto de variables de interés.

\subsection{Reincidentes que se especializan}

Como se planteó en la segunda sección, basándose en Blumstein y sus colaboradores, ${ }^{29}$ entenderemos la especialización como la tendencia a cometer la misma tipología de delitos en períodos sucesivos de tiempo. Morales et $a l .{ }^{30}$ realizan una primera aproximación al estudio de la especialización penitenciaria en el caso chileno evaluando si los reincidentes retornan a la cárcel por el mismo delito que egresaron durante el año 2007. Esta operacionalización del concepto logra capturar la especialización delictual en los casos en que la persona se especializa en el mismo delito por el cual egresó de la cárcel. Sin embargo, no refleja la especialización para patrones delictuales más complejos. Tal sería el caso, por ejemplo, si la primera condena de una persona es por una infracción a la ley del tránsito y todas las sucesivas condenas son por infracciones a la ley de drogas. En tal caso, la persona quedaría clasificada como alguien que no se ha especializado en un tipo de delito debido a que las condenas posteriores no coinciden con el delito de referencia. Lo mismo puede suceder cuando una persona tiene varios delitos de referencia (los cuales están todos asociados a una misma condena), pero reincide en sólo uno de ellos o es más frecuente su reincidencia por alguno de ellos.

Estas limitaciones de los cálculos de especialización a partir de una condena de referencia surgen sólo si existen combinaciones de trayectorias delictuales complejas. Por lo mismo, es necesario indagar si ello ocurre con la población reincidente chilena para determinar si es relevante o no modificar el método de cálculo de la especialización. Como se muestra en la Tabla 1, este parece ser precisamente el caso. La tabla resume los registros de sucesivas reincidencias de personas que egresaron de la cárcel por el delito de mayor incidencia (en este caso, hurto) según el tipo de delito por el cual volvieron a ser condenados. Como puede verse, muchos casos de condenas posteriores no son por el delito de hurto. De hecho, la tabla es consistente con la existencia de un grupo significativo de casos que egresaron de la cárcel por el delito de hurto y volvieron reiteradamente a ella por otras tipologías de delitos, no siendo posible a simple vista determinar si se trata de un grupo que se especializó o no en esos otros delitos. ${ }^{31}$

\footnotetext{
${ }^{29}$ BLUMSTEIN/COHEN/ROTH/VISHER, Criminal careers, cit. nota $\mathrm{n}^{\circ} 4$.

${ }^{30}$ MORALES/MUÑOZ/WELSCH/FÁBREGA, La reincidencia, cit. nota $n^{\circ} 1$.

${ }^{31}$ Nótese que la tabla es consistente además con la presencia de escalamiento en delitos de personas que fueron condenadas por hurto y posteriormente por delitos no violentos y violentos. La verificación de dicha hipótesis deberá ser abordada en estudios posteriores.
} 
FÁBREGA, Jorge; MORALES, Ana María; MUÑOZ, Nicolás “Delito y especialización en Chile".

Tabla 1. Registro de reincidencias de personas que egresaron de la cárcel tras una condena de hurto el 2007 según tipo de delito de las siguientes cuatro condenas/*

\begin{tabular}{lrrrr}
\hline \multirow{2}{*}{ Delito de la condena de reincidencia } & Reincidencias entre los años 2007 y 2010 \\
\cline { 2 - 5 } & Primera & Segunda & Tercera & Cuarta \\
\hline Cuasidelitos & 0 & 0 & 0 & 0 \\
Contra fe pública & 0 & 1 & 0 & 0 \\
Contra la libertad/intimidad de las personas & 48 & 29 & 18 & 13 \\
Leyes especiales & 53 & 29 & 7 & 5 \\
Delitos económicos & 14 & 4 & 4 & 2 \\
Delitos funcionarios & 1 & 1 & 1 & 0 \\
Ley de drogas & 65 & 27 & 15 & 9 \\
Ley de tránsito & 15 & 4 & 3 & 1 \\
Delitos sexuales & 7 & 4 & 1 & 1 \\
Faltas & 174 & 100 & 55 & 42 \\
Homicidios & 10 & 6 & 0 & 0 \\
Hurtos & 1.573 & 988 & 573 & 310 \\
Lesiones & 55 & 19 & 15 & 0 \\
Otros delitos & 39 & 22 & 12 & 4 \\
Otros delitos contra propiedad & 151 & 73 & 40 & 21 \\
Robos & 210 & 100 & 50 & 18 \\
Robos no violentos & 218 & 126 & 58 & 18 \\
\hline
\end{tabular}

*/Se excluyen casos con cinco o más reincidencias

Fuente: Elaboración propia

Ejercicios similares con otros delitos de referencia también muestran patrones complejos de relación entre tipologías de delitos. Para ilustrar dicha complejidad, la Figura 1 muestra la relación entre delitos para toda la población reincidente en la forma de una red. En la figura, cada círculo representa un tipo de delito de referencia. El tamaño de cada círculo es proporcional a la relevancia relativa del tipo de delito en la base de datos. Cada flecha que conecta dos círculos (o que parte desde un círculo y termina en el mismo) representa los casos de reincidencia de personas que egresaron por un delito y reingresaron a la cárcel por otro (o por el mismo delito) según la dirección de la flecha. El grosor de cada flecha es proporcional al número de casos que representa. Así por ejemplo, el círculo más grande es aquel del delito de hurto, donde la mayor reincidencia se presenta precisamente como una flecha autorreferente de delitos de hurto sobre sí mismo. No obstante, también se observan flechas que conectan hurtos con otras categorías delictuales, en correspondencia con los datos mostrados en la Tabla 1. Por lo tanto, la figura pone de manifiesto que existe una alta interrelación entre los distintos tipos de delitos que es visualmente evidente. Por ende, para dar cuenta de esa complejidad y diversidad, es necesario desarrollar una métrica distinta a la especialización basada en delitos de referencia.

Figura 1. Interconexiones entre tipos de delitos desde la primera a la segunda condena 


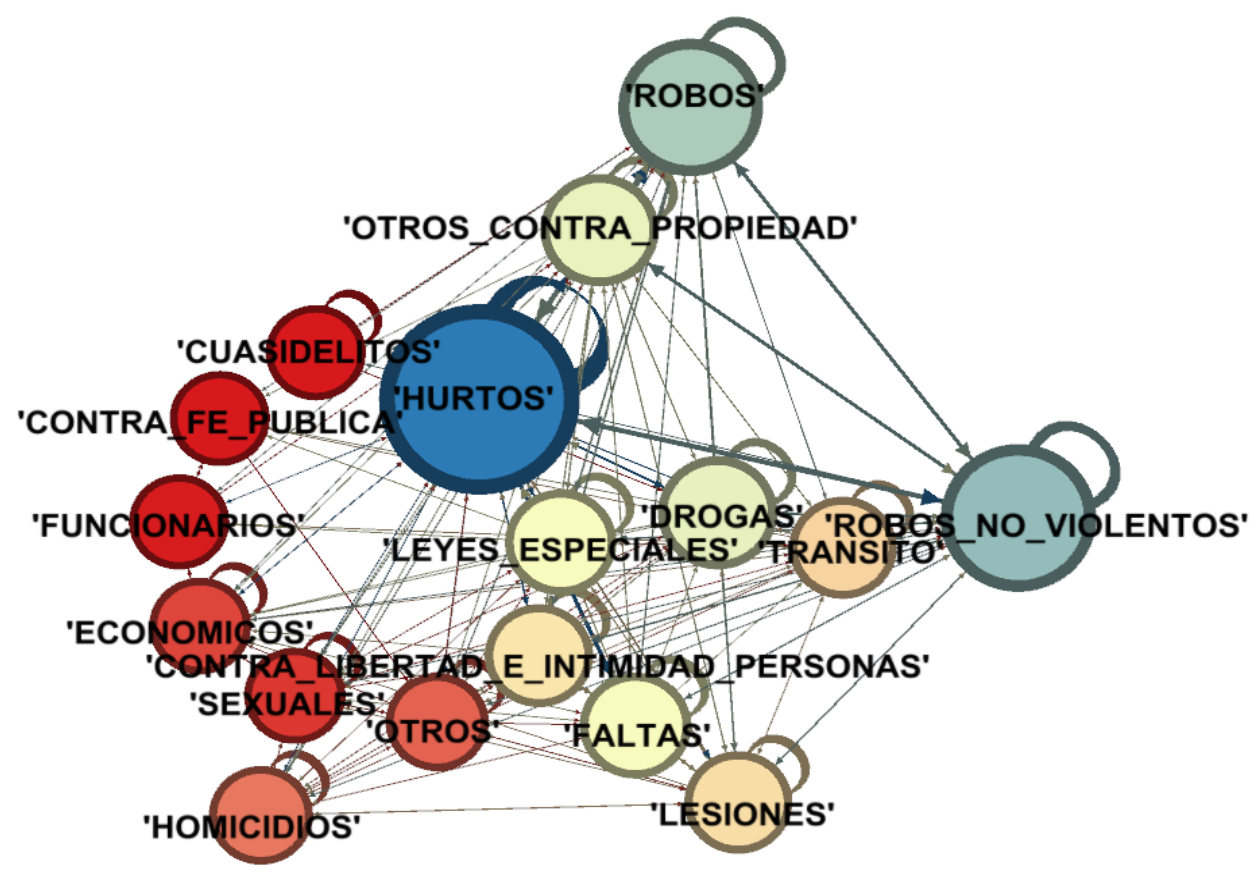

Fuente: Elaboración propia

Para evitar las omisiones de casos asociados a medir la especialización a partir de delitos de referencias, se construyó una variable de especialización que asocia a cada individuo la categoría delictual que más se repita en su historial durante el período de observación independientemente del delito por el cual haya egresado por primera vez desde el 2007. Esto implicó elaborar una matriz con tantas filas como el número existente de reincidentes y tantas columnas como el número de categorías delictuales. En cada celda ij de la matriz se calculó el número de veces que el individuo $i$ fue condenado por delitos en la categoría $j$ para todas las reincidencias que tuvo en el período de observación. De este modo, si un individuo egresó por hurto y retornó a la cárcel cuatro veces por robo no violento y dos veces por tráfico de drogas, en su celda relacionada al delito de hurto aparecerá un 1, en su celda relacionada a robo no violento aparecerá un 4 y en su celda relacionada a delitos de ley de drogas aparecerá un 2 . Una vez generados los valores para cada individuo en cada tipología de delito, se identificó la especialización de cada individuo como aquella correspondiente al mayor valor de su $\operatorname{serie}^{32}$ (en el ejemplo anterior, la persona sería clasificada como especializada en robos no violentos con cuatro reincidencias).

\section{Resultados}

\footnotetext{
${ }^{32}$ En este contexto, el indicador de especialización contemplará a aquellas personas que presentan, al menos, una reincidencia por un mismo delito, siempre y cuando represente el mayor valor de la serie. Bajo esta lógica, si bien se definió "la especialización delictual como la tendencia a cometer la misma tipología de delitos en períodos sucesivos de tiempo", este ejercicio tiene como objetivo explorar indicios de especialización delictual, toda vez que no se dispone de un período de seguimiento más prolongado de los sujetos egresados de las unidades penales del país. Este método se fundamenta en otros estudios en la materia. Para más detalles véase LO/KIM/CHENG, "Offense specialization”, cit. nota n 10 .
} 
FÁBREGA, Jorge; MORALES, Ana María; MUÑOZ, Nicolás “Delito y especialización en Chile".

La Tabla 2 resume la estimación de los niveles de especialización obtenidos para el conjunto de la población reincidente. De acuerdo a esta formulación, un 35\% no muestra indicios de especialización y un $65 \%$ sí presenta especialización con distintos grados de intensidad en alguna categoría delictual.

Tabla 2. Especialización

\begin{tabular}{lc}
\hline Especialización & $\mathrm{N}$ \\
\hline Sin especialización & 2.991 \\
Una reincidencia & 3.526 \\
Dos reincidencias & 1.082 \\
Tres reincidencias & 503 \\
Cuatro reincidencias & 263 \\
Cinco o más reincidencias & 172 \\
\hline Total & 8.537 \\
\hline
\end{tabular}

Fuente: Elaboración propia

Una comparación entre la especialización calculada en la forma propuesta en este estudio y la calculada vía reincidencia específica en Morales y sus colaboradores ${ }^{33}$ es resumida en la Tabla 3. En casi todos los casos, si bien persisten diferencias entre distintas categorías delictuales, los resultados sugieren niveles de especialización mayores a los estimados mediante la reincidencia específica. En particular, la categoría delictual con mayor reincidencia en Chile (el delito de hurto) aumenta desde un $71 \%$ a un $90 \%$ de especialización. No obstante lo anterior, aumentos igualmente significativos se observan en las otras categorías delincuenciales, a excepción de los delitos de robos y robos no violentos.

Tabla 3. Comparación entre especialización y reincidencia específica. Submuestra* de delitos con mayor número de reincidentes

\begin{tabular}{|c|c|c|c|}
\hline \multirow[b]{2}{*}{ Delito por el que egresó de la cárcel } & \multicolumn{2}{|c|}{ Especialización } & \multirow{2}{*}{$\begin{array}{l}\text { Reincidencia } \\
\text { específica** }\end{array}$} \\
\hline & $\begin{array}{c}\text { Clasificados como } \\
\text { especializados }\end{array}$ & $\%$ & \\
\hline Hurtos & 2.380 de 2.631 & $90 \%$ & $71,1 \%$ \\
\hline Robos no violentos & 1.262 de 2.514 & $50 \%$ & $51,8 \%$ \\
\hline Robos & 654 de 1.428 & $46 \%$ & $41,5 \%$ \\
\hline Otros contra la propiedad & 227 de 515 & $44 \%$ & $26,2 \%$ \\
\hline Ley de drogas & 337 de 392 & $86 \%$ & $54,6 \%$ \\
\hline Lesiones & 114 de 271 & $42 \%$ & $23,8 \%$ \\
\hline Ley de tránsito & 125 de 176 & $71 \%$ & $51,8 \%$ \\
\hline Leyes especiales & 146 de 156 & $94 \%$ & $30,5 \%$ \\
\hline Faltas & 120 de 152 & $79 \%$ & $32,1 \%$ \\
\hline Contra la libertad /intimidad de las personas & 99 de 103 & $96 \%$ & \\
\hline Homicidios & 19 de 41 & $46 \%$ & \\
\hline Global & 5.546 de $8.537 * * *$ & $65 \%$ & \\
\hline
\end{tabular}

*/ Corresponde al 97,8\% de la población reincidente

**/ Tomado de Morales et al. (2012)

${ }^{33}$ MORALES/MUÑOZ/WELSCH/FÁBREGA, La reincidencia, cit. nota $\mathrm{n}^{\circ} 1$. 
Polít. crim. Vol. 9, № 18 (Diciembre 2014), Art. 7, pp. 521-542.

[http://www.politicacriminal.cl/Vol_09/n_18/Vol9N18A7.pdf]

***/El total incluye los casos por el resto de las tipologías no incorporadas en la tabla ( $2.2 \%$ del total)

Fuente: Elaboración propia

Por último, se estima la probabilidad de especialización a partir de la historia de delitos previos, edad, género y duración del último delito. La Tabla 4 muestra la descripción de las variables utilizadas en la estimación, la cantidad de observaciones, promedio, desviación estándar y rangos de valores. Es importante constatar que la variable especialización es conceptualmente ordinal y no cardinal, es decir, la distancia que separa los niveles de especialización "1" y "2" no necesariamente es igual a la que separa a los niveles "2" y "3". Para este tipo de variables dependientes ordinales es necesario utilizar técnicas de estimación con los métodos de logit o probit ordenados.

Tabla 4: Descripción de las variables

\begin{tabular}{|c|c|c|c|c|c|}
\hline Variable & Observaciones & Promedio & $\begin{array}{c}\text { Desviación } \\
\text { estándar }\end{array}$ & Min & Max \\
\hline Especialización & 8.537 & 1,067237 & 1,143695 & 0 & 5 \\
\hline $\begin{array}{l}\text { Reincidencias * } \\
\text { (veces) }\end{array}$ & 8.537 & 1,862247 & 1,273606 & 1 & 7 \\
\hline Género( $\mathrm{F}=0, \mathrm{M}=1)$ & 8.502 & 0.886262 & 0.317511 & 0 & 1 \\
\hline Edad (tramos) $* *$ & 8.293 & 2,456409 & 1,438458 & 1 & 6 \\
\hline $\begin{array}{l}\text { Historial }(0=\operatorname{Sin} \\
\text { antecedentes, } \\
1=\text { Con } \\
\text { antecedentes })\end{array}$ & 8.537 & 0,451329 & 0,497655 & 0 & 1 \\
\hline $\begin{array}{l}\text { Duración } \\
\text { (días) }^{* * *}\end{array}$ & 8.461 & 529,5439 & 838,0485 & 0 & 7.034 \\
\hline
\end{tabular}

La Tabla 5 resume los resultados de modelos de estimación utilizando probit ordenados. En concordancia con la literatura internacional, los signos de los coeficientes de cada variable explicativa en el modelo sugieren que en Chile existen trayectorias de especialización crecientes a medida que aumentan las reincidencias y la edad, pero no es concluyente respecto a que los primerizos sean menos proclives a la especialización que aquellos con historial de registros delictuales previos a la condena por la cual egresaron por primera vez durante el 2007; tampoco parece incidir la duración del tiempo de privación de libertad por la condena que inicia el período de observación. Por último, las mujeres presentarían mayores niveles de especialización que los hombres. Ahora bien, es importante notar que si bien la dirección del efecto de cada variable puede inferirse a partir de los coeficientes de la tabla 5 estas estimaciones no son directamente interpretables en su magnitud. Para ello es necesario calcular los efectos marginales de cada variable sobre la especialización.

Tabla 5 - Estimación de la propensión a la especialización 
FÁBREGA, Jorge; MORALES, Ana María; MUÑOZ, Nicolás “Delito y especialización en Chile".

\begin{tabular}{|c|c|c|c|c|c|c|}
\hline & (1) & (2) & (3) & (4) & (5) & (6) \\
\hline reincidencias $^{1}$ & $\begin{array}{c}0.908 * * * \\
(69.17)\end{array}$ & $\begin{array}{c}0.913 * * * \\
(68.64)\end{array}$ & $\begin{array}{c}0.918 * * * \\
(67.92)\end{array}$ & $\begin{array}{c}0.913 * * * \\
(67.22)\end{array}$ & $\begin{array}{c}0.910 * * * \\
(66.74)\end{array}$ & $\begin{array}{c}0.857 * * * \\
(32.32)\end{array}$ \\
\hline genero $^{2}$ & & $\begin{array}{c}-0.586^{* * *} \\
(-15.27)\end{array}$ & $\begin{array}{c}-0.581 * * * \\
(-15.05)\end{array}$ & $\begin{array}{c}-0.578 * * * \\
(-14.97)\end{array}$ & $\begin{array}{c}-0.570 * * * \\
(-14.61)\end{array}$ & $\begin{array}{c}-0.600 * * * \\
(-10.31)\end{array}$ \\
\hline edad $^{3}$ & & & $\begin{array}{c}0.0623 * * * \\
(7.17)\end{array}$ & $\begin{array}{c}0.0585 * * * \\
(6.64)\end{array}$ & $\begin{array}{c}0.0551 * * * \\
(6.20)\end{array}$ & $\begin{array}{c}0.0627 * * * \\
(5.51)\end{array}$ \\
\hline historial $^{4}$ & & & & $\begin{array}{c}0.0733 * * \\
(2.84)\end{array}$ & $\begin{array}{c}0.0529 * \\
(1.98)\end{array}$ & $\begin{array}{c}0.0262 \\
(0.78)\end{array}$ \\
\hline duracion $^{5}$ & & & & & $\begin{array}{c}-0.0000567 * * * \\
(-3.40)\end{array}$ & $\begin{array}{c}-0.00000261 \\
(-0.14)\end{array}$ \\
\hline Contante & & & & & & $\begin{array}{c}-0.550^{* * * *} \\
(-7.51)\end{array}$ \\
\hline _cut1 & $\begin{array}{c}0.986 * * * \\
(41.19)\end{array}$ & $\begin{array}{c}0.458 * * * \\
(10.88)\end{array}$ & $\begin{array}{c}0.621 * * * \\
(13.04)\end{array}$ & $\begin{array}{c}0.640 * * * \\
(13.30)\end{array}$ & $\begin{array}{c}0.597 * * * \\
(12.02)\end{array}$ & \\
\hline _cut2 & $\begin{array}{c}2.622 * * * \\
(77.31)\end{array}$ & $\begin{array}{c}2.123 * * * \\
(44.96)\end{array}$ & $\begin{array}{c}2.286 * * * \\
(43.38)\end{array}$ & $\begin{array}{c}2.305 * * * \\
(43.36)\end{array}$ & $\begin{array}{c}2.261 * * * \\
(41.55)\end{array}$ & \\
\hline _cut3 & $\begin{array}{c}3.671 * * * \\
(78.22)\end{array}$ & $\begin{array}{c}3.200 * * * \\
(56.47)\end{array}$ & $\begin{array}{c}3.370 * * * \\
(54.39)\end{array}$ & $\begin{array}{c}3.389 * * * \\
(54.35)\end{array}$ & $\begin{array}{c}3.347 * * * \\
(52.82)\end{array}$ & \\
\hline _cut4 & $\begin{array}{c}4.594 * * * \\
(75.68)\end{array}$ & $\begin{array}{c}4.157 * * * \\
(61.02)\end{array}$ & $\begin{array}{c}4.332 * * * \\
(59.19)\end{array}$ & $\begin{array}{c}4.353 * * * \\
(59.14)\end{array}$ & $\begin{array}{c}4.311 * * * \\
(57.85)\end{array}$ & \\
\hline _cut5 & $\begin{array}{c}5.488 * * * \\
(72.16) \\
\end{array}$ & $\begin{array}{c}5.077 * * * \\
(61.93)\end{array}$ & $\begin{array}{c}5.263 * * * \\
(60.67)\end{array}$ & $\begin{array}{c}5.286 * * * \\
(60.63)\end{array}$ & $\begin{array}{c}5.243 * * * \\
(59.55)\end{array}$ & \\
\hline $\mathrm{N}$ & 8537 & 8502 & 8259 & 8259 & 8186 & 8186 \\
\hline
\end{tabular}

t statistics in parentheses; $* \mathrm{p}<0.05, * * \mathrm{p}<0.01, * * * \mathrm{p}<0.001$

${ }^{1} /$ Número de reincidencias; ${ }^{2} /$ Dummy con valor 1 si es hombre; ${ }^{3} /$ Edad a la fecha del primer egreso de la cárcel el 2007; ${ }^{4}$ Dummy con valor 1 si posee un historial de condenas previas a la condena por la que egresó el 2007; ${ }^{5} /$ Duración de la condena por la que egresó el 2007.

Fuente: Elaboración propia

Las Figuras 2, 3 y 4 muestran los efectos marginales (en base al modelo 6 de la Tabla 5) de las variables que fueron robustas a lo largo de los distintos modelos (la reincidencia, la edad y el género). La Figura 2 muestra cómo cambia la probabilidad que una persona esté especializada en un tipo de delito con cada sucesiva reincidencia. De acuerdo a estas estimaciones, un condenado que reincide una vez tiene una probabilidad de 0,48 de estar ingresando en una carrera delictual especializada y uno que ha reincidido cinco o más veces con toda seguridad se ha especializado en algún tipo de categoría delictual.

\section{Figura 2: Estimación de la probabilidad de especializarse en una categoría delictual en relación al} aumento de reincidencias 
Polít. crim. Vol. 9, Nº 18 (Diciembre 2014), Art. 7, pp. 521-542.

[http://www.politicacriminal.cl/Vol_09/n_18/Vol9N18A7.pdf]

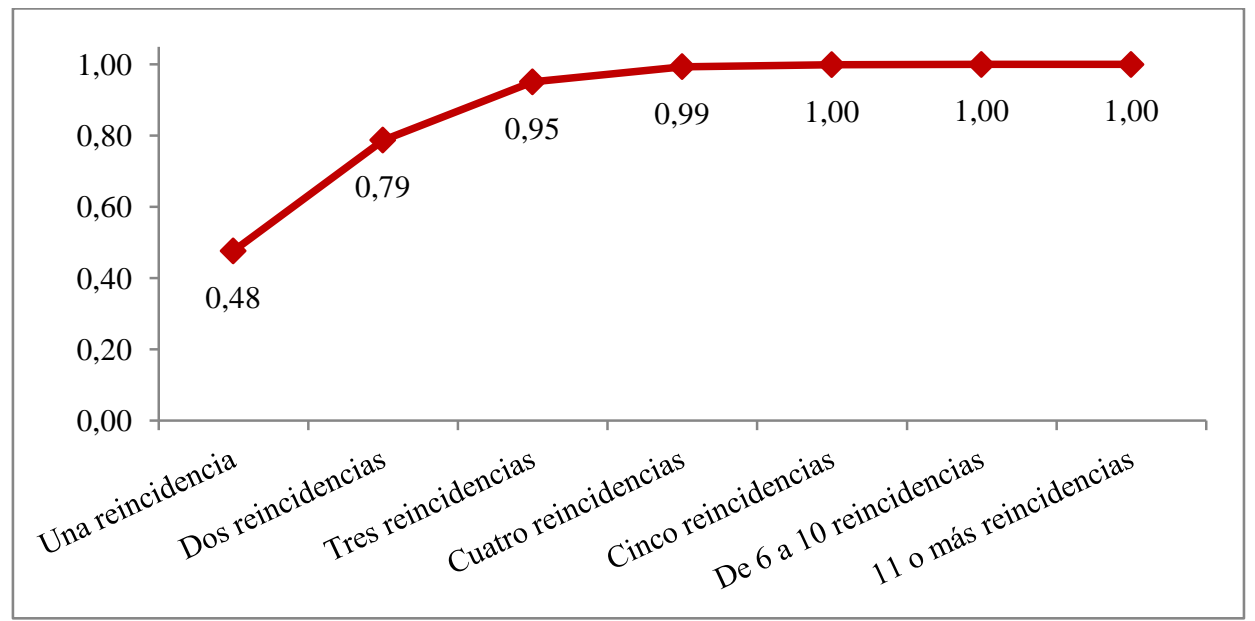

Fuente: Elaboración propia

Por otra parte, la Figura 3 muestra que la probabilidad de especializarse en un tipo de delito aumenta aproximadamente entre 0,01 y 0,02 cada cinco años, de modo tal que una persona reincidente entre 18 y 23 años de edad tiene una probabilidad de 0,73 de especializarse, mientras una que tenga el doble de edad tendría una probabilidad estimada de 0,78 de hacerlo.

Figura 3: Estimación de la probabilidad de especializarse en una categoría delictual en relación al rango etáreo

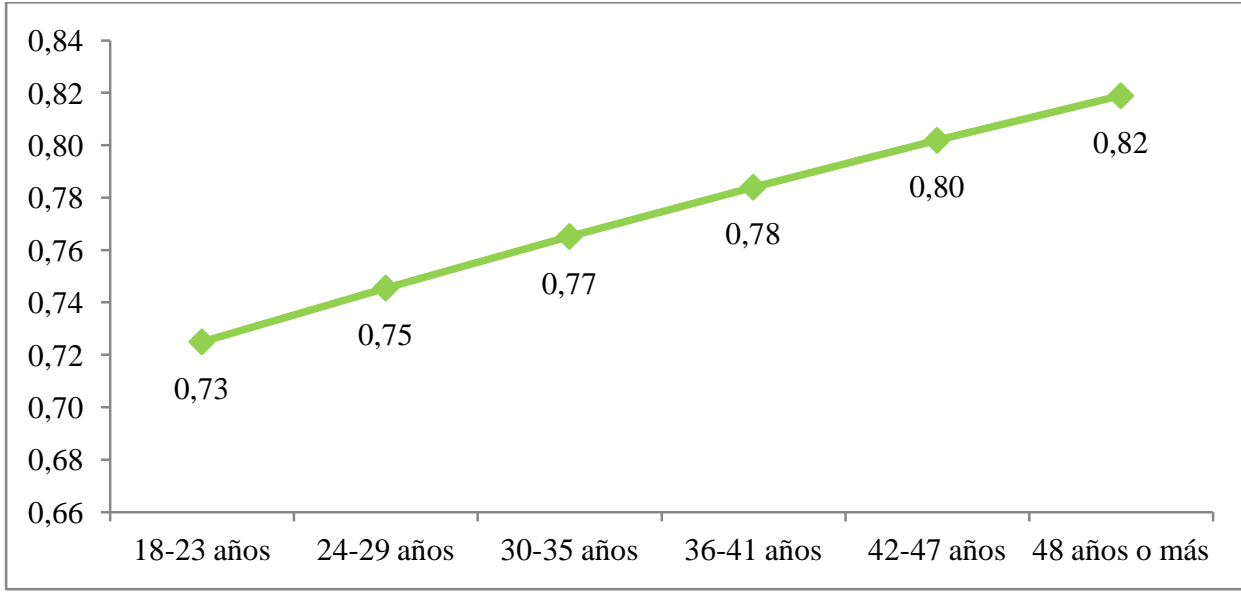

Fuente: Elaboración propia

Finalmente, la Figura 4 muestra la probabilidad de especialización de mujeres y hombres, siendo mayor en las primeras $(89 \%)$ que en los segundos $(73 \%)$, un resultado que es concondarte con las estimaciones de Tumminello y colaboradores ${ }^{34}$ para Suecia. En esta diferencia de comportamiento según género cumple un rol central que las mujeres presenten mayores niveles de concentración que los hombres en la comisión de delitos de hurto. Por ejemplo, del total de las mujeres reincidentes en la muestra (967 casos) existen $671(69 \%)$ que egresaron de la cárcel el 2007 (año de referencia para el seguimiento) por un

\footnotetext{
${ }^{34}$ TUMMINELLO/EDLING/LILJEROS/ MANTEGNA/SARNECKI, “The phenomenology", cit. nota n 25.
} 
FÁBREGA, Jorge; MORALES, Ana María; MUÑOZ, Nicolás “Delito y especialización en Chile".

delito de hurto. En cambio, si bien en volumen son más los hombres que egresaron ese año de la cárcel por delitos de hurto y volvieron a ella en calidad de reincidentes (2,047 casos), ese grupo sólo representa un $27 \%$ de los 7,535 reincidentes de género masculino.

Figura 4: Estimación de la probabilidad de especializarse en una categoría delictual en relación al rango género

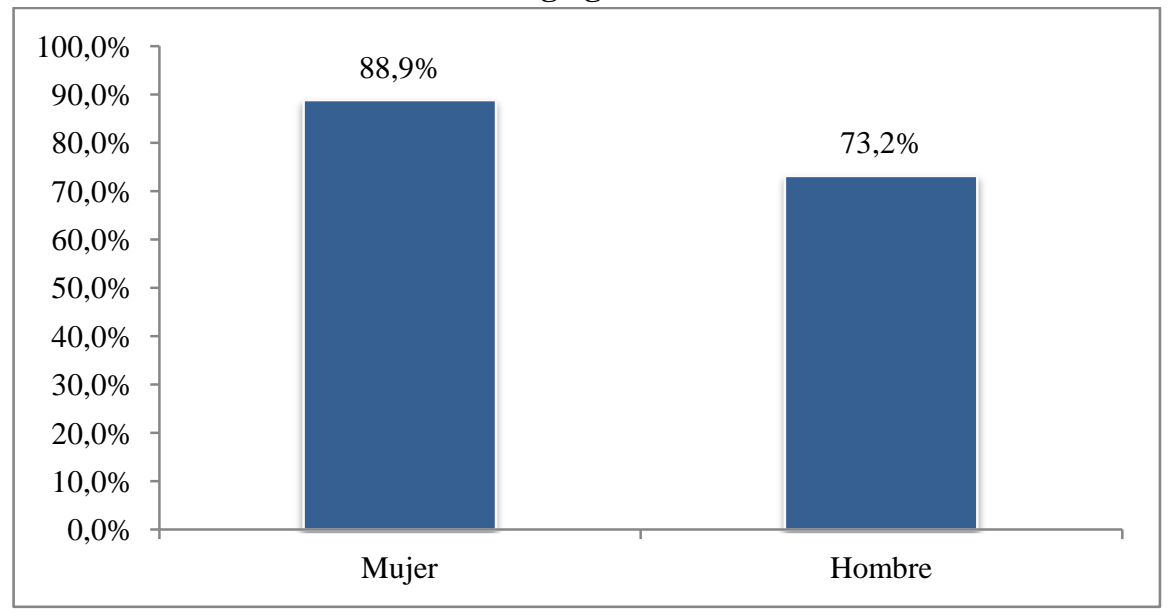

Fuente: Elaboración propia

\section{Conclusiones}

Como se observó en el capítulo introductorio, comprender el grado en que un infractor puede especializarse en términos delictivos tiene importantes implicancias en materia de política pública. De esta forma, el conocer los patrones de especialización, permite predecir de mejor manera el comportamiento esperado al egreso de la cárcel y facilitar la toma de decisiones a los policy-makers en áreas como la prevención delictual, su control y la reinserción social de los infractores de ley. Así, considerando que uno de cada dos egresados de un establecimiento penal retorna a la cárcel en la calidad procesal de condenado, dimensionar y comprender esos patrones de especialización constituye una tarea útil y necesaria.

El presente estudio sugiere que los niveles de especialización, aunque variados, son mayores a los estimados en análisis nacionales anteriores. ${ }^{35}$ Específicamente, se observó una especialización de un $65 \%$ de la población reincidente, es decir, aproximadamente dos tercios de las personas que egresan de la cárcel y reinciden, se especializarán en una categoría delictual. Bajo este promedio general, se ocultan patrones diversos de reincidencia, los cuales, en términos generales, sugieren que existen diferencias de especialización por género y por edad lo que es consistente con la literatura internacional. Por otra parte, en este estudio se estima que la probabilidad de especialización tiende a uno hacia la cuarta reincidencia. Por lo tanto, como los tipos de delitos que eventualmente vuelva a cometer un recluso si llega a reincidir son crecientemente predecibles, entonces, las políticas destinadas a lograr su reinserción social podrían beneficiarse de generar diseños diferentes para reclusos por delitos diferentes. En cuanto a la tipología de los

\footnotetext{
${ }^{35}$ MORALES/MUÑOZ/WELSCH/FÁBREGA, La reincidencia, cit. nota ${ }^{\circ} 1$.
} 
delitos, tres categorías de delitos concentran un 50\% de los casos de especialización, éstos son los delitos de hurto $(27,9 \%)$, robos no violentos $(14,8 \%)$ y robos $(7,7 \%)$. Ello es consistente con la literatura internacional sobre la materia.

Por otra parte, la presente investigación no logró contar con mayor información respecto a otras variables que pueden ser de vital interés. En concreto, variables sociodemográficas, más allá del género y edad, no pudieron ser estimadas, sin embargo, es relevante tenerlas en consideración en futuras investigaciones al respecto.

Con estos antecedentes en conocimiento, creemos que la evidencia que ofrece el presente estudio es importante en materia de política pública, pues permite contar con variables de interés para las áreas de análisis criminal, clasificación de la población penal y especialmente en materia de rehabilitación y reinserción. En esta última materia, resulta interesante el desarrollo observado en la experiencia comparada que ha tendido a diversificar la oferta programática existente tanto en intervenciones ambulatorias como intramuros, en base a variables como la edad, el género y el tipo de delitos, a través de la existencia de programas acreditados. Así, cada vez es más frecuente encontrar programas especializados en infractores adolescente o adultos jóvenes, en mujeres, y especialmente aquellos que atienden a la tipología delictual involucrada a través de oferta orientada a otorgar intervención en infractores que se han especializado en cometer delitos violentos, delitos contra la propiedad no violentos, delitos sexuales, violencia intrafamiliar, manejo en estado de ebriedad, entre otros programas especializados. ${ }^{36}$

\footnotetext{
${ }^{36}$ Véase como ejemplo, el desarrollo de intervenciones especializadas de acuerdo a variables como la edad, género y especialización delictual del infractor en Inglaterra y Gales, a través del desarrollo de programas acreditados denominados Offender Behavior Programmes (OBPs) en: NATIONAL OFFENDER MANAGEMENT SERVICE, The Correctional Services Accreditation Panel Report 2010-2011, 2011.
} 
FÁBREGA, Jorge; MORALES, Ana María; MUÑOZ, Nicolás “Delito y especialización en Chile".

\section{BIBLIOGRAFÍA}

ANDRESEN, M., "Crime Specialization across the Canadian Provinces", Revue canadienne de criminologie et de justice pénale, 51:1 (2009), pp. 31-53.

BARLOW, H. y FERDINAND, T., Understanding delinquency, New York: Harper Collins, 1992.

BRITT, C., "The measurement of specialization and escalation in the criminal career: An alternative modeling strategy", Journal of Quantitative Criminology, 12:2 (1996), pp. 193-222.

BLUMSTEIN, A., COHEN, J. y FARRINGTON, D., "Criminal career research: Its value for criminology”, Criminology, 26:1 (1988), pp. 1-35.

BLUMSTEIN, A., COHEN, J. Y ROTH, J. y VISHER, C., Criminal careers and "career criminals", Report of the Panel on Research on Criminal Careers, National Research Council, Washington, D.C.: National Academy Press, 1986.

FARRINGTON, D., "The Integrated Cognitive Antisocial Potential (ICAP) Theory", en: FARRINGTON, D. (Ed.), Advances in Criminological Theory, Integrated Developmental \& Life-Course Theories of Offending, New Brunswick: Transaction Publishers, 2005.

GENDARMERÍA DE CHILE, Estadísticas de Población Atendida por Gendarmería, 2013. Disponible en: http://www.gendarmeria.cl

GOTTFREDSON, M., "Offender Classifications and Treatment Effects in Developmental Criminology: A Propensity/Event Consideration", Annals of the American Academy of Political and Social Science, Vol. 602 (2005), 46-57.

KLEIN, M., "Offense specialization and versatility among juveniles", British Journal of Criminology, 24 (1984), 185-194.

LATTIMORE, P., VISHER, CH. y LINSTER, R., "Specialization in Juvenile Careers: Markov Results for a California Cohort", Journal of Quantitative Criminology, 10 (1994), pp. 291-316.

LAUB, J. y SAMPSON, R., Shared Beginnings, Divergent Lives: Delinquent Boys to Age 70, Cambridge, MA: Harvard University Press, 2005.

LO, C., KIM, Y. y CHENG, T., "Offense specialization of arrestees: An event history analysis", Crime and Delinquency, 54:3 (2008), pp. 341-365.

LOEBER, R., FARRINGTON, D., STOUTHAMER-LOEBER, M., MOFFITT, T. y CASPI, A., "The development of male offending: Key findings from the first decade of the Pittsburgh Youth Study", Studies on Crime and Prevention, 7 (1988), pp. 141171.

McGLOIN, J., SULLIVAN, C., PIQUERO, A. y PRATT, T., "Local life circumstances and offending specialization/versatility: Comparing opportunity and propensity models", Journal of Research in Crime and Delinquency, 44:3 (2007), pp. 321-346.

MOFFITT, T., "Adolescence-Limited and Life-Course Persistent Antisocial Behavior: A Developmental Taxonomy", Psychological Review, 100 (1993), pp. 674-701.

MORALES, A., MUÑOZ, N., WELSCH, G. y FABREGA, J., La reincidencia en el sistema penitenciario chileno. Santiago: Fundación Paz Ciudadana, Hanns Seidel Stiftung y Universidad Adolfo Ibáñez, 2012.

NATIONAL OFFENDER MANAGEMENT SERVICE, The Correctional Services Accreditation Panel Report 2010-2011, 2011. Disponible en: 
Polít. crim. Vol. 9, Nº 18 (Diciembre 2014), Art. 7, pp. 521-542.

[http://www.politicacriminal.cl/Vol_09/n_18/Vol9N18A7.pdf]

https://www.gov.uk/government/uploads/system/uploads/attachment_data/file/217276 /correctional-services-acc-panel-annual-report-2010-11.pdf (última visita: 15.01.2014).

PIQUERO, A., "Frequency, specialization, and violence in offending careers", Journal of Research in Crime and Delinquency, 37: 4 (2000), pp. 392-418.

PIQUERO, A. y BUKA, S., "Linking juvenile and adult patterns of criminal activity in the Providence cohort of the National Collaborative Perinatal Project", Journal of Criminal Justice, 30: 4(2002), pp. 259-272.

PIQUERO, A., OSTER, R., MAZEROLLE, P., BRAME, R. y DEAN, Ch., "Onset age and offense specialization", Journal of Research in Crime and Delinquency, 36:3(1999), pp. 275-299.

SAMPSON, R. y LAUB, J., "A Life-Course View of the Development of Crime", Annals of the American Academy of Political and Social Science, 602 (2005), pp. 12-45.

SOOTHILL, K., FITZPATRICK, C. y FRANCIS, B., Understanding Criminal Careers, Cullompton, Devon: Willan, 2009.

SULLIVAN, C., MCGLOIN, J., PRATT, T. y PIQUERO, A., "Rethinking the "norm" of offender generality: Investigating specialization in the short-term", Criminology, 44:1(2006), pp. 199-233.

TUMMINELLO, M., EDLING, C., LILJEROS, F., MANTEGNA, R. y SARNECKI, J., "The phenomenology of specialization of criminal suspects", PLOS ONE, 8:5 (2013), pp. 1-8. 
FÁBREGA, Jorge; MORALES, Ana María; MUÑOZ, Nicolás "Delito y especialización en Chile".

\section{Anexo: Características de la población reincidente}

Figura A1: Distribución de la población reincidente según número de reincidencias.

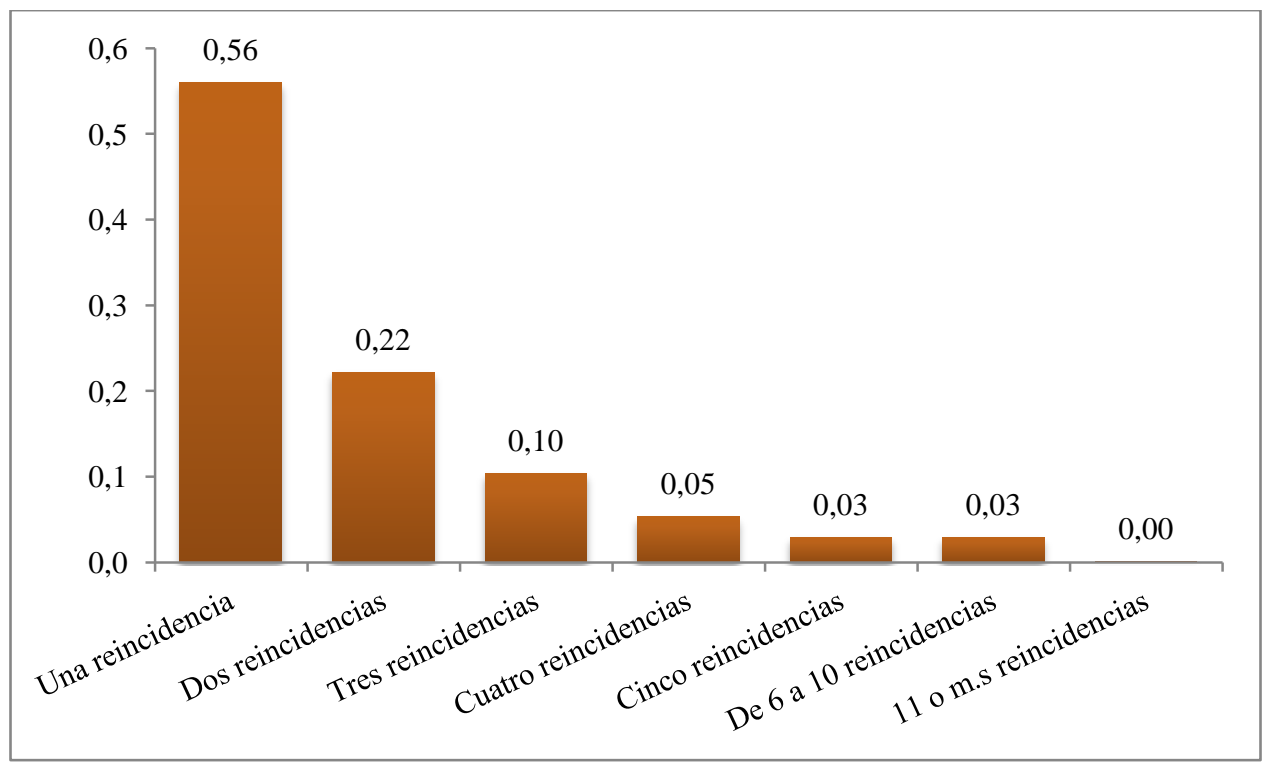

Fuente: Elaboración propia

Figura A2: Distribución de población reincidente por género

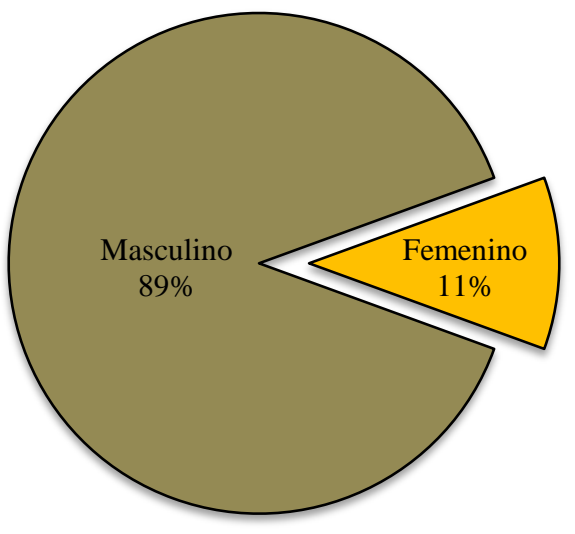

Fuente: Elaboración propia 
Polít. crim. Vol. 9, № 18 (Diciembre 2014), Art. 7, pp. 521-542.

[http://www.politicacriminal.cl/Vol_09/n_18/Vol9N18A7.pdf]

Figura A3: Establecimiento penal desde el que egresó el interno según tipo de administrador

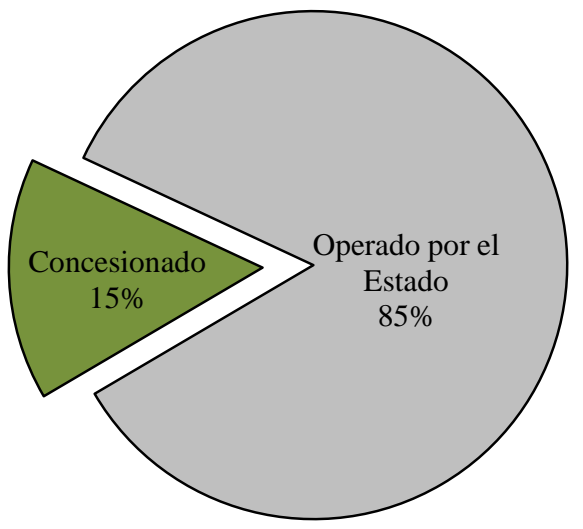

Fuente: Elaboración propia

Figura A5: Distribución etárea de la población reincidente

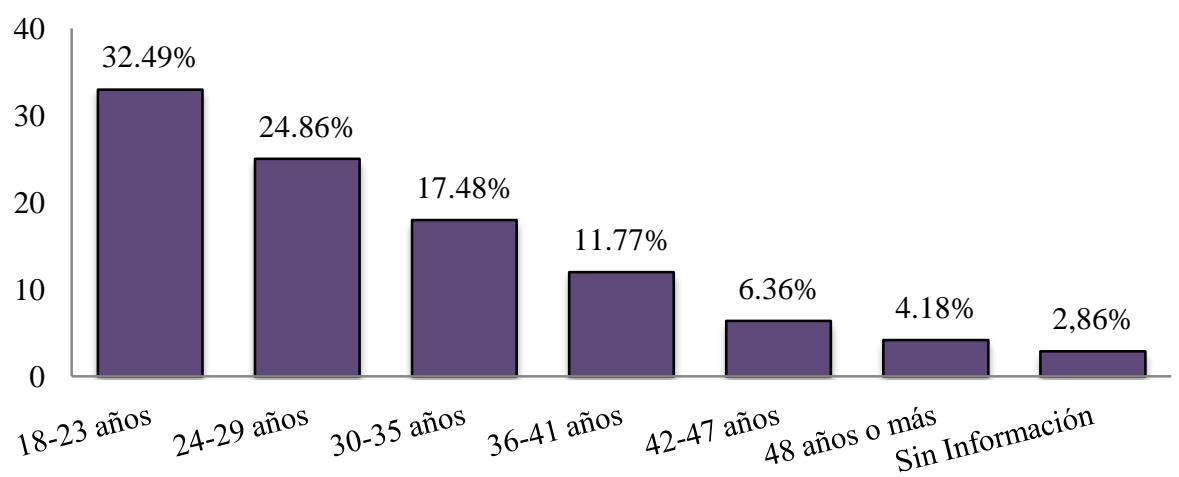

Fuente: Elaboración propia

Figura A6: Reincidentes según historial de condenas previas

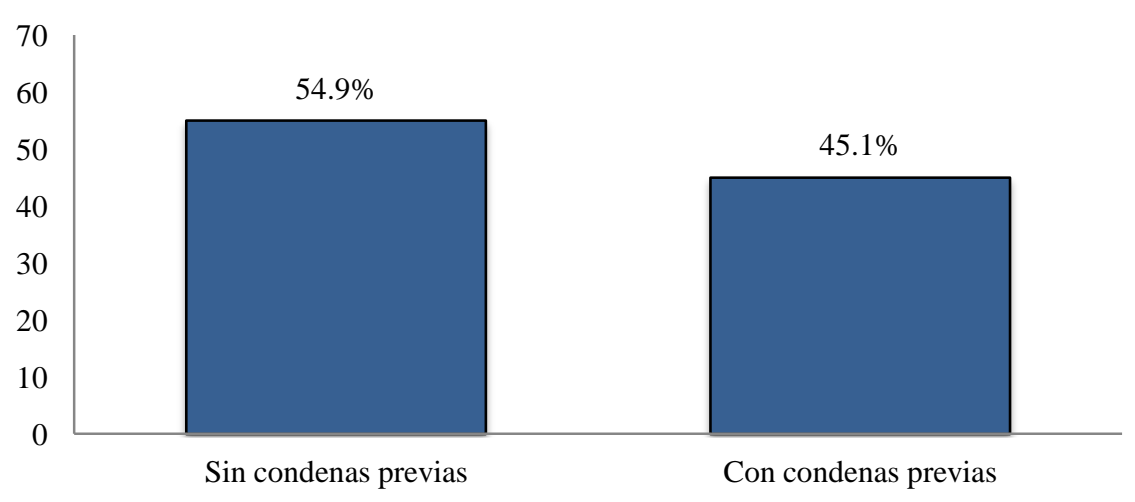

Fuente: Elaboración propia 
FÁBREGA, Jorge; MORALES, Ana María; MUÑOZ, Nicolás “Delito y especialización en Chile".

Tabla A1: Distribución geográfica de los reincidentes

\begin{tabular}{lcc}
\hline Región de Cumplimiento de la Condena & No. & $\%$ \\
\hline Arica y Parinacota & 203 & $2,4 \%$ \\
Tarapacá & 438 & $5,1 \%$ \\
Antofagasta & 834 & $9,8 \%$ \\
Atacama & 213 & $2,5 \%$ \\
Coquimbo & 272 & $3,2 \%$ \\
Valparaíso & 1.072 & $12,6 \%$ \\
O'Higgins & 452 & $5,3 \%$ \\
Maule & 479 & $5,6 \%$ \\
Biobio & 666 & $7,8 \%$ \\
Araucanía & 327 & $3,8 \%$ \\
Los Rios & 149 & $1,7 \%$ \\
Los Lagos & 364 & $4,3 \%$ \\
Aysén & 67 & $0,8 \%$ \\
Magallanes & 54 & $0,6 \%$ \\
Metropolitana & 2.947 & $34,5 \%$ \\
\hline Total & 8.537 & $100,0 \%$ \\
\hline
\end{tabular}

Fuente: Elaboración propia

Tabla A2: Delito por el cual egresó en la condena previa a su primera reincidencia en el período de observación

\begin{tabular}{lccc}
\hline $\begin{array}{l}\text { Tipo de Delito de referencia ( referido a la condena } \\
\text { por la cual egresó por primera vez durante el 2007) }\end{array}$ & No. & $\%$ & $\begin{array}{c}\% \\
\text { acumulado }\end{array}$ \\
\hline Hurtos & 2.722 & $31,9 \%$ & $31,9 \%$ \\
Robos No Violentos & 1.633 & $19,1 \%$ & $51,0 \%$ \\
Robos & 1.277 & $15,0 \%$ & $66,0 \%$ \\
Otros Delitos contra la Propiedad & 557 & $6,5 \%$ & $72,5 \%$ \\
Delitos Ley de Drogas & 542 & $6,3 \%$ & $78,8 \%$ \\
Delitos de Leyes Especiales & 356 & $4,2 \%$ & $83,0 \%$ \\
Faltas & 323 & $3,8 \%$ & $86,8 \%$ \\
Lesiones & 279 & $3,3 \%$ & $90,1 \%$ \\
Delitos contra la Libertad e Intimidad de las Personas & 264 & $3,1 \%$ & $93,2 \%$ \\
Delitos Ley de Tránsito & 198 & $2,3 \%$ & $95,5 \%$ \\
Homicidios & 126 & $1,5 \%$ & $97,0 \%$ \\
Otros Delitos & 116 & $1,4 \%$ & $98,3 \%$ \\
Delitos Económicos & 61 & $0,7 \%$ & $99,0 \%$ \\
Delitos Sexuales & 36 & $0,4 \%$ & $99,4 \%$ \\
Violencia Intrafamiliar & 31 & $0,4 \%$ & $99,8 \%$ \\
Delitos contra la Fe Pública & 7 & $0,1 \%$ & $99,9 \%$ \\
Delitos Funcionarios & 5 & $0,1 \%$ & $100,0 \%$ \\
Cuasidelitos & 4 & $0,0 \%$ & $100,0 \%$ \\
\hline Total & 8.537 & $100.0 \%$ & \\
\hline
\end{tabular}

Fuente: Elaboración propia 